\section{Peer-assisted Learning (PAL) as an Instructional Tool in Dental Interns in Corona Virus Disease (COVID-19) Scenario}

Sir,

The value of psychological tools in dental education is established. ${ }^{1}$ I read with interest the article about peer-assisted learning (PAL) as an instructional tool in undergraduate dental education by Ehsan. ${ }^{2}$ In the current novel coronavirus disease 2019 (COVID-19) pandemic, we are using PAL as an instructional tool to teach sterilisation protocols, doning and doffing of protective personal equipment (PPE) and oropharyngeal and nasopharyngeal swab procedures for dental interns posted in our institution. Medical, dental and nursing disciplines actively play their role in PAL with topics subdivided into: a) Sterilisation protocol of hand washing, donning and doffing of PPE, and b) Theoretical and practical demonstration of oropharyngeal and nasopharyngeal swab procedures. In this context, apart from academic excellence, teamwork and positive feedback, PAL paves the way to reduce the burden of workload among the healthcare professionals (medical, dental and nursing) in the COVID-19 catastrophe. More studies are needed regarding PAL as an instructional tool in COVID-19 scenario.

\section{CONFLICT OF INTEREST:}

The author declared no conflict of interest.

\section{AUTHOR'S CONTRIBUTION:}

TS: Contributed in the conception or design of the work; or the acquisition, analysis, or interpretation of data for the work; and drafting the work or revising it critically for important intellectual content; and final approval of the version to be published; and agreement to be accountable for all aspects of the work in ensuring that questions related to the accuracy or integrity of any part of the work are appropriately investigated and resolved.

\section{REFERENCES}

1. Shamim T. Psychological tools in oral pathology specialty for rapid clinical and histopathological interactive session. Med J Armed Forces India 2021; 77(1):116. doi: 10.1016/ j.mjafi.2019.10.001.

2. Ehsan AA. Peer-assisted learning (PAL) as an instructional tool in undergraduate dental education. J Coll Physicians Surg Pak 2020; 30(11):1184-7. doi: 10.29271/jcpsp.2020. 11.1184.

Thorakkal Shamim

Department of Dentistry, Government Taluk Head Quarters Hospital, Malappuram, India

Correspondence to: Dr. Thorakkal Shamim, Department of Dentistry, Government Taluk Head Quarters Hospital, Malappuram, India

E-mail: shamu3duad@gmail.com

Received: January 21, 2021; Revised: April 23, 2021;

Accepted: April 23, 2021

DOI: https://doi.org/10.29271/jcpsp.2021.JCPSPCR.CR144

\section{AUTHOR'S REPLY:}

Sir,

I am thankful to Dr Shamim for interest in my article titled “Peerassisted learning (PAL) as an instructional tool in undergraduate dental education" and comments on it. I agree that PAL is a very effective instructional tool in this Covid-19 pandemic scenario. Likewise, many institutes in Pakistan can utilise this tool, as there is widespread closure of standard face-to-face training of dental professionals during these difficult times. It will also be an important tool in reflection, feedback, and teaching patient safety and preparing for practice.

Ambreen Afzal Ehsan

Department of Orthodontics, Altamash Institute of Dental Medicine, Karachi, Pakistan

Correspondence to: Department of Orthodontics, Altamash Institute of Dental Medicine, Karachi, Pakistan

E-mail:drafzalehsan@gmail.com 